A major purpose of the Technical Information Center is to provide the broadest dissemination possible of information contained in DOE's Research and Development Reports to business, industry, the academic community, and federal, state and local governments.

Although a small portion of this report is not reproducible, it is being made available to expedite the availability of information on the research discussed herein. 
L $\lambda-U 21--83-1525$

DERA $01263 t_{x}$

\section{N ?TICE}

DORTIONS OF THIS REPTRT ARE ILLEGIBLE. $N$

has been reprodiced from !ine best available

copy to permit the broadest possible avail-

ability.

Los Alamos National Laboratory to operaled by the Un!veralty of Callfornla for the United 8tates Department of Energy under contraet W-7405-ENG-30.

TITLE: ANOMALOUS SUR.FACE IMPEDANCE IN REENTRANT FERROMAGNETIC SUPERCONDUCTORS

Author(s): C. Y. Huang, G. Kozlowski, F. Mancini, M. B. Maple, H. Matsumoto, C. E. 01 son, H. Umezawa, and J. P. Whitehead

SUSMITTED TO: 17 th International Conference on Low Temperature Physics, Aug. 15-22, 1984, Karlsruhe, West Germany

\title{
IHS, I.AIMFR
}

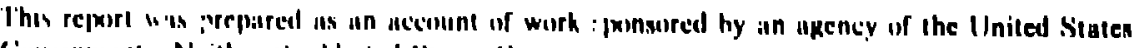

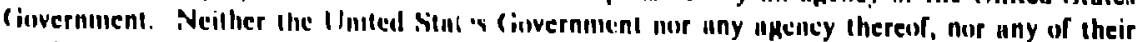
employees, milkes uny warriuly, express or implied, ur ussumes uny lepul liability or respannsihility fur the acesurus. completeness, or use fulness of uny infurmulion, appuralus, prokluct, ur

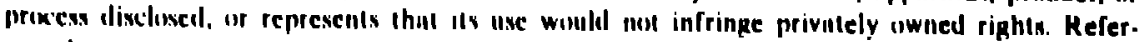

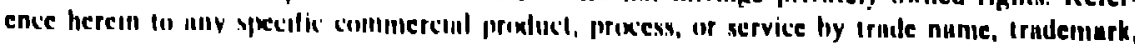
manulacturer, "t utherwise dies not necessurily constitute or imply its endorsenent, reconnmenilution, of fuvorimg hy the llumled sintes (juverument or uny ugency thereuf. The viewn and ominions of nuthors expressed herenn do nol necessarily stute or rellect thesse of the Inited Situles d: vernment or uny anency thereoli.
\end{abstract}

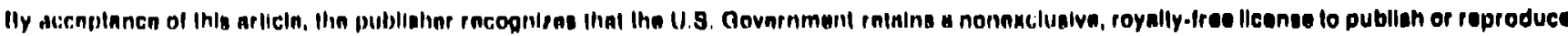
the nublisned torm of this contributien, or to allow olliers to do so, lor U.8. Ooverninent purposen.

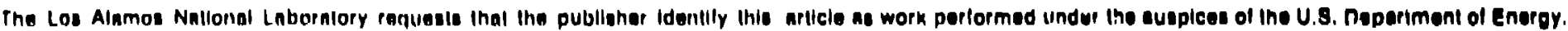

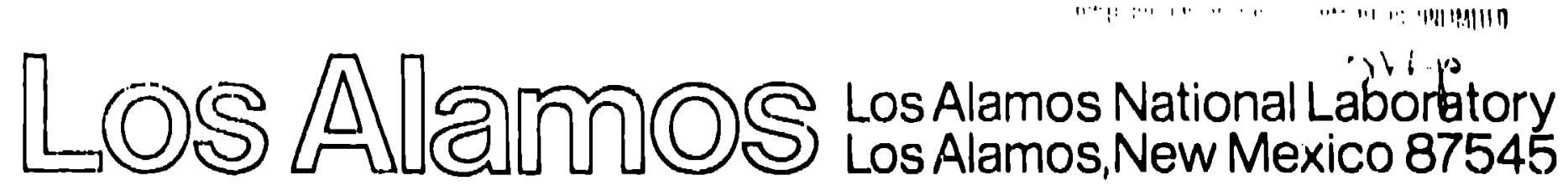




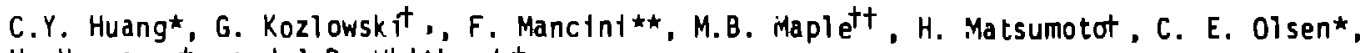

$H$. Umezawa $t$. and J.P. Whit thead $t$

* Los Alamos National Laboratory, Los Alamos, New Mexico 87545, U.S.A.

+ University of Alberta, Edmonton, Aiberta, Canada T6G 2J1

* Univers!ta di Salerno, Instltuto di Fisica, B4lo0 Salerno, Italy

tt University of Cailfornia, San Diego, La Jolla, California 92093, U.S.A.

For ErRh ${ }_{4} B_{4}$, owing to the critlcal spin fluctuations Just above $T_{5}\left(>T_{C \imath}\right)$, the critic:l tempera. ture at which surface ferromagnet $15 m$ appiars, the reciprocal penetration depth, $A^{-1}$, decreases smoothly as $T$ decreases toward $T_{s}$. For $\mathrm{Er}_{0} .5^{\mathrm{HO}_{0}} .5^{\mathrm{Rh}} \mathrm{h}_{4} \mathrm{~B}_{4}$, the decrease in $i-i$ for $T>T_{C a}$ is very small, and $\lambda^{-1}$ decreases abruptiy at $T_{c 2}$.

$\mathrm{ErRh}_{4} \mathrm{~B}_{4}$ has been invesîlgated intrnsively It becomes superconducting at $\mathrm{r}_{\mathrm{Cl}}=8.7 \mathrm{~K}$ and reenters the normal state at $T_{c} c 20.8 \mathrm{~K}$. The persistent current screens the long-wave corrconents of the excharige interaction between raie eartil magnetic moments, giving risc to the onset of a spin-periodtc pliase at $T_{p}\left(2 T_{c 2}\right) .(1,2)$ However. due to the reduction of the per'sistent current screening in tne nelghborhood of the sample surface, it has becn shown the oretically (3) that uniform ferromignetism within a magnetic penetration dept.n of the surface appears below $T_{5}\left(>T_{C 2}\right)$, In view of the fact

that microwaves sample a vclume near a surface determinnd by the penetration depth, $\lambda$, they would be expected to provide a useful pirobe in the search for this surface erromagnetic state,

We have employed a microwave spectrometer with a sample ( $0.5 \mathrm{~mm} \times 22 \mathrm{~mm} \times 26 \mathrm{~mm})$ glued to one side of a rectangular TEloi cavtly operated at $29.3 \mathrm{GHz}$. The temperature dependence of $\lambda$ changes the effective size of the cavity, and, hence, gives rise to the shift of the esonance frequency of thr cavity, allowing $\lambda$ to be obtained simply by measu:ing the frequency shift of the cavity, (4) Our system is stable enough to measure a frequency shift as small as $250 \mathrm{~Hz}$, which cnables us to measure $\lambda$ to an accuracy of a few $\hat{\Lambda}$. In addition to frlligl, for comparison, we have also investi-

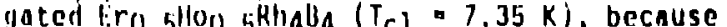
only its llo magnetle moments order furromagne. clcally at $T_{C 2}(2.70 \mathrm{~K})(5,6)$ with a meanfleld typn of transition. Figures 1 and 2 show our resuits. The effects of the absence of spin fluctuations in $\mathrm{Er}_{0 .} 5^{\mathrm{HO}_{2}}$. $5^{\mathrm{Rh}} \mathrm{P}_{4}$ is clearly displayed by the sharp drop in $\lambda^{-1}$ at $1 \mathrm{c}$. Indicating that $T_{5}<T_{c}$. The graduai decrease of $\lambda-i$ In ErRfinba as $i$ is decreased toward $T_{i} 215$ consistent witir the prodfction that $T_{62}<T_{p} \times T_{5}$. in a non-magnetle superconcluctor the arfier 1mpedance may be expressed as a simple relation involving the London penetration depth. (7) However, this formula is no ionger valid in a magnetic superconductor owing to the effect of the spin fluctuations. For our calculation, we consider a semi-infinite superconductor filling the hali-space $z>0$, with a surface at $z$ - $U$. From the definition of the surface Impedance, we define the effective penetration depth as (7)

$$
\lambda(\omega)=\operatorname{Re} \int_{0}^{\infty} d z b(\omega ; z) / h(\omega ; 0) .
$$

where $b$ and $h$ are the amplituiles of $B$ and $H$, respectively.

By assuming that the effects of the pair breaking associater with the spin fluctuations and the polarization of the superconducting electrons induced through the i-f interaction are negligible, the London penelration depth $\lambda_{L}(T)$ may be computed using the standard BCS formula. Utllizing the Maxwell equations, we obtain in the paramagnetic state

$$
\begin{aligned}
& \text { whern } \\
& F=\lambda_{L}(T)\left[a+a_{-}\left(a_{+}+a_{-}+i \lambda_{L}(T)+n \mu \lambda_{L}(T)\right]\right. \\
& \quad G=n\left[a^{2}+a_{+} a_{-}+a^{2}+\| \lambda_{1}(T)\left(a_{+}+a_{-}\right)-n\right]
\end{aligned}
$$$$
\lambda(w)=R_{B}(F / G)
$$

Here $a_{+}$and $a_{\text {- }}$ are given by

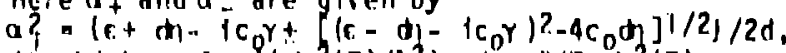
In which $n=1-\left\{\left(\lambda \lambda^{2}(T) / \delta ?\right), d=D / T_{m} \lambda 2(T)\right.$, $c=T / T_{m}-1, c_{0}=4 \pi c / T_{m}$ and $Y=\omega \tau / 4 \pi$.

$T_{\text {Ill }}$ is tha normal state Curle temperature, $C$ the Curle constant, and $D$ the stiffness constant. Near $T_{5}, \lambda(0)$ o $\left(T_{-}-T_{5}\right)^{-T}$.

in Fig. I we present the theoretical values for the inverse of the characteristic length $\lambda(w)$ (solid curve) calculated from En. (1) for ErRhglla together with the experimental values (ctrcles). The whystcal parameters used are 
$T_{m}=1.0 \mathrm{~K}, d_{0}=0.2529 \times 10^{-2}$, and $T_{P}=$ $0.85 \mathrm{~K}$. This gives a value for $\lambda_{L}(0)^{\mathrm{P}}=908 \mathrm{~A}$. We also present the result of the static limlt (dash-dotted curve) using a non-local kernel $(3,8)$ together with the parameters $K_{B}=4$, $d_{j}=0.4254 \times 10^{-2}$ and $\lambda(0)=749 \mathrm{~A}$.

The dashed curve is the $B C^{-1}(T)$

$w i$ th the parameter choice $\lambda_{L}(0) \cdot 1184 \mathrm{~A}$. We note that the effect of the spin fluctuations, as evidenced by the departure of the data from the BCS fitting, is quite pronounced, particularly at low temperatures.

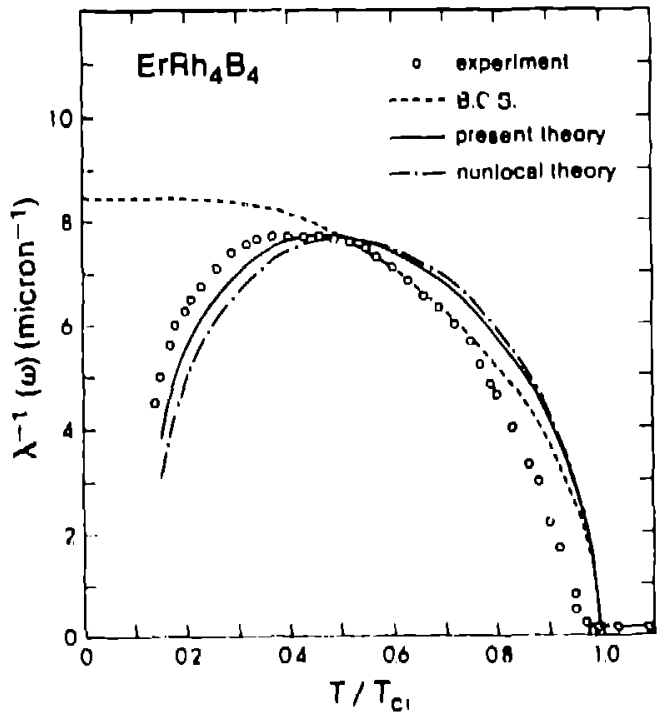

Fis. 1. Penetration depth $\lambda(\omega)$ for ErRh484.

In Fig. 2 the experimental data of $\lambda^{-1}(\omega)$ for $\mathrm{Er}_{0} \mathrm{H}_{\mathrm{H}} \mathrm{H}_{5} \mathrm{Rh}_{4} \mathrm{~B}_{4}$ are presented (c)rcles) together with the BCS $\lambda^{-1}(T)$ (dashed curve) with the parameter chotce $\lambda_{L}(0)=1186 \mathrm{~A}$. The experimental $\lambda=(\omega)$ shows a mild deviation from the BCS result above $T_{C 2}$ and a discontinuous Jump to 1 ts nurmal value at $T$. $T$. indicating that there is no additfonal magnetic transistion abnve $T_{C}$ ? ('.e... $T_{5}<T_{C 2}$ ). (i is givell by the mean value of the values obtalned in the Er and llo case. The theory (solld curve) yiclds do - 1.0, ich is very large, indlcating that $T_{5}$ is 11 below $T_{C}$. Fur compar1son, the theoretical curve for $y$. 0 (1, e. $w$ - 0$)$ is aiso presented, and shows a sinail decrease at lower temperature due to the fluctuation effect. Therefore, the present alialysis suggests that the opparnnt suppression of the spin fluctuations in the superconducting state is due tor $\mathrm{T}_{5}<\mathrm{T}^{\mathrm{c}} \mathrm{z}$ and also to the effect of thir sptn relaxation time.

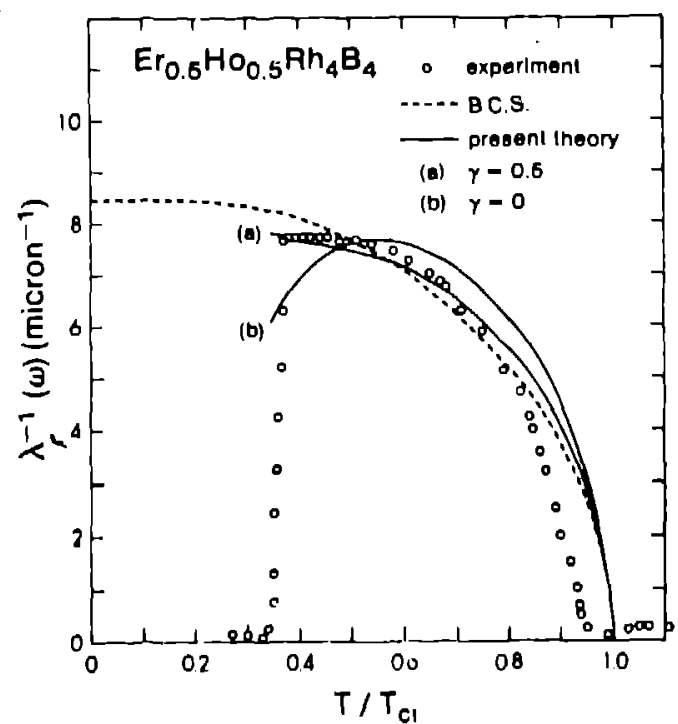

F1y. 2. Penetration depth $\lambda(\omega)$ for $\mathrm{Er} .1 \mathrm{H}^{\mathrm{l} O} \mathrm{5}_{5} \mathrm{Ph}_{4} \mathrm{~B}_{4}$.

In summary, the effect of the spin fluctuations can play an importan'. role in determining the surface impedance in magnetic superconductors. In particular, the surface impedance of ErPhaBd clearly mant fests the effect of the critical fluctuations in the surface mangetization around $T_{c}$. The surface tmpedancs of Ero. ${ }_{5} \mathrm{HoO}_{0} \mathrm{Ph}_{4} \mathrm{P}_{4}$ exhiblts a rather snlooth dependence on the temperature down to $T_{c} 2$, where 1 t changes abruptly due to the first order magnetic ransistion, ind 1 cating the suppression of the spin fluctuations in the superconducting state.

\section{ACKNOWLEOGEMENTS}

Thy s work was supported by the II. S. Department of Energy and NSERC, Canada,

REFERENCES

(T) S.K. Sinha, G.W. Crabtree, D.G. Hinks, and H. Mouk, Phys, Rev. Lett. 48 (1982) 950.

(2) H. Matsumoto, H. Umezawa and M. Tachiki, Solld State Commun. 31, (1979); 157 E.1, Blount and C.M. Yarma, Phys. Rev. Lett. 42 (1979) 1079 .

(3) A. Kotant, M. Tachikt H. Marsumnto and H. Umezawa, lhys. Rev. B23 (1981) 5960.

(4) F.J. Racliford, Ph.D. Thesis, Case Western Reserve University 275 (unpublished).

(5) S. Mackaha, J.L, Smi ih, and C.Y. lluang, Phys. Rev. B22 (;980) 164 .

(6) H.A. Mook, W.C. Koehler, M.B. Maple, Z. Fisk, D.C Johnstom, and L.D. Woolf. Phys. Rev. Has (1982) 372.

(7) T.E. Faber arid A.B. Plppard, Proc. Roy. Soc. ilonclon) A.31 (1955) 336.

(B) F. Mancint and M. Fusco-girard, Phys, lett. $95 \mathrm{~A}(1983) 917$. 